\title{
Methodology Enlightenments of Contemporary Marxist Literary Criticism on Contemporary Literary Geography Research of Shaanxi
}

\author{
Yunxia Gao ${ }^{1,2}$ \\ ${ }^{1}$ College of Literature and Journalism, Sichuan University, Chengdu, Sichuan Province, China \\ ${ }^{2}$ Xi'An Fanyi University, China
}

Keywords: literary geography; contemporary Shaanxi literature; methodology.

\begin{abstract}
Contemporary Marxist Literary Criticism edited by Francis Mulhern provides an introduction to the development, current trends and evolution of Marxist Literary Criticism. The book represents the diversity and fundamental continuities of Marxism. Texts selected in the book cross the domain of time, space and cultural history, and provide methodology enlightenments for the contemporary literary geography research of Shaanxi. It includes not only the common core methods of Marxism, but also new ideas and conclusions which blend with contemporary thought. It enables us to stand in the position of historical materialism, re-examine the complex geographical spaces in literary works of specific regions, and further explores the relationship between literature genre and geography.
\end{abstract}

\section{Introduction}

Literary geography is a new subject created by Chinese scholars in 1980s. For a long time, literary studies have focused on longitudinal research of time and history, and ignored the horizontal research of geography and space. Literary geography tries to make up for the deficiency, and construct a new cross-subject on literary research. As a province with advanced culture and literature, literary studies in Shaanxi have been focusing on local cultural characteristics over the years, and discussed the relationship between literature and regions. However, with the further development of literary geography, studies on the complex interactions between literary and geographical elements are not enough; macro perspective and methodology researches of literary geography are even less. The contemporary theory of Marxist Literary Criticism covers many fields, and can provide the theoretical basis for interdisciplinary research, further explore the significance and connotation of texts, and represent the relationship between literature genre and geography.

\section{Adhering to the Principles of Historical Materialism}

The basic standpoint of Marxist Literary Criticism is to observe the society with the view of production mode. From this standpoint, the reading and writing process of texts should be understood from the social context. That is, "meaning is the result of production." [1] Since the occurrence and growth of people's awareness is a part of material practice, rather than purely spiritual activity, the materiality of natural environment must be included in literature research. Scholars not only need to study the effects of geographical environment on literary creation, but also should investigate the reactions of literary creation on geographical environment. In the context of literary geography, researchers must pay attention to the interactions between the relationship of man and region, and the relationship between writers, texts and readers. How does the writer produce imaginary geographic space? What is the relationship between the imaginary geographical space and the real geographic space? Which kind of writing style and narrative modes does the writer use? What are the differences in the choice of literary geography mechanism for writers with different personalities and from different periods? What are the differences between the earlier and later literary works of a writer? Which kind of aesthetic experience does the writer convey to readers through the construction of aesthetic geographical space, and how these experiences affect the life and living environment of modern people? All these problems show the richness and extension of literary geography research. 
In fact, researches on the relationship between literature and geography have been represented in ancient poetics and literary theories, as well as contemporary researches on local literature and regional culture. But these studies tend to emphasize on the influences of geographical features on the styles of literature and art works. By using Marxism literary theory, a more systematic theoretical framework of literary geography can be established. Both the effects of geographical environment on literature and art production, and the influences of ideological connotation on geographical environment can be investigated. Thus, the attitudes of people who have power of discourse towards people from different regions and cultural environments can be found. These attitudes determine the manifestation of literature research in different geographical spaces. Scholar Jin-xiang Liu holds that, "there are two levels of geographical space: one is the geographic space of actual life, the other is people's understanding of their own and others' geographical spaces under certain geographical environment awareness." The former should be evaluated through scientific and rational methods, while the latter should be judged from people's geographical and cultural values. It can be found in artists' aesthetic expressions of geographical spaces. Therefore, the task and value of literary geography is to reveal the aesthetic treatment of writers and artists on geographical space, and to convey the historical attitude and humanistic position of geographical environment.

\section{Focusing on the Analysis of Relationship Between Plot and Space}

The main purpose of literary geography is the study of literary space. Literary geography tries to rediscover the literature space which has been neglected for a long time. As all things exist in time and space, literature cannot exist without the two dimensions of time and space, and the study of literature cannot be separated from the two dimensions of time and space. The history study of literature also requires three-dimensional pictures on space to fully reproduce the overall perspective of works. Thus, the development and deepening of space research is consistent with the inherent need of building a literature research model which combines space and history at the same time, and can make up for the deficiencies of current Chinese literature study. The most notable literary achievements of contemporary Shaanxi are the novels, which witness the "modernity" of Chinese development, and serve as the representative of regional ecological literature. The comprehensive analyses of the spaces in these novels can be carried out from multi angles and directions.

In the article Jane Austin and Empire, Edward W. Said seeks a new method of interpretation on narrative space. In modern society, people take narrative time as a basic element of literature research. This sequential concept of time is the embodiment of the simple Europe-centered international pattern. "From Lukacs and Proust, we always believe that the plots and structures of novels are mainly composed by time, and ignore the fundamental roles of geographical range and space". [4] Based on the point, he believes that the "counterpoint relationship" between reality and literary works should be identified, because the "original pattern of counterpoint is spatial, not temporal". [5] "Counterpoint" is a musical term. Said uses this term to indicate space positions, search the space relationship between one event and another, and investigate the right relations between two large geographical spaces, East and West, in the synchronic time. Said stands in the postcolonial position, tries to analyze the relationship between gardens in Jane Austin's novel Mansfield Park and exotic colonial gardens in distance and establish a national independent space theory. His emphases on geography and space in narrative texts provide us with new perspectives of studying plots in Chinese novels.

First of all, from the macro point of view, the "counterpoint" method is used in the perspective of world literature. In this perspective, the study of regional literature and the comparison of literature from different regions are of great significance. Regional feature is an important feature of geography, while the definite task of geography is to study all things filled in the space. "The research objects of geography are regional features of human and nature; an important method of geography is the regional comparison method. As a kind of regional science, geography occupies an important position in the scientific system. The value of geography is to understand human and nature from the perspective of "three-dimensional" reality of time and space. [6] Geography is different from history, which studies events from the sequence of time. Geography studies spatial phenomena which occur at 
the same time. Meanwhile, the spatial distributions of human phenomena on different regions are not uniform, and the variation regularities of one element are different in different regions. Therefore, it is necessary to analyze the internal structure of different geographical regions, including the relationships between different elements, their roles in the whole regions, and the relationships between regions which constraint their development and change processes. Reflected in the literary geography, it is the comprehensive reflection of geographical features, cultural appearances, literary forms and writing styles.

Secondly, from the micro perspective, the analyses on specific plots necessarily involve analyses of specific scenes. From the counterpoint method, personal relationships between citizens and farmers, elites and the common people, collective and individuals, as well as their expressions and changes during the modernization process of China can be seen. Therefore, we need to pay attention to the relationships between structures of specific places and writers' geographic perceptions, and investigate how the authors generate text geography with their own unique characteristics, since there is a close relationship between text geography and the psychology of the writer. "Place analysis is a systematic psychological study of our inner life. In the theater of our memory, the background preserves main characters...... Space preserves time in the tens of thousands of small holes. This is the role of space." [8] We can explore various meanings of space through the "places", and finally discover the extensive meaning of narrative plots.

\section{Emphasizing the Relationship Between Literature Genre and Geography}

At present in China, there are few articles on literary geography take the perspective of literature genre, which is related to Chinese scholars' neglect of stylistic research. In ancient China, the study on literature genre was developed. But In modern times, due to the influences of western academic systems, and the promotion of "new poetry" "new novel" and "new drama" since the May Fourth Vernacular Movement, the stylistic study has separated with ancient stylistic theories. Especially in the revolution period, the attention to content of literature weakens researchers' awareness of stylistic criticism. As a matter of fact, the stylistic study is a central issue in literary studies. As Meng Wang said: "Literary style is the externalization of personality..... The change of literary concept reflects in the change of literary style. The exploration of literary creation is the innovation of literary style. The grotesque of literary conception reflects in absurd literary styles. The rigid expression of literary thought is represented in stereotyped literary style. The maturity of literary personality is the maturity of literary style. Literary style is the most direct expression of literature." [9] In Chinese literary theory, literary style is a general term which refers to a wide range of elements, such as writing style, literary genre and a variety of form. Therefore, literary style is a unique perspective for the study of literary geography.

In the article The Moment of Truth: the Geography of Modern Tragedy, Franco Moretti mentions that literature genre has "time limit" as well as "space boundaries". [9] His literary geography theory starts from literature genre, studies European and American literature, and focuses on the distributions and reasons of different genres - novels and tragedies. Since each genre has its own origin and course of development, the historical consciousness in literature research is strong. Moretti researches literature from the perspective of geographical space. He takes Germany, the most representative cultural geography model in the modern period as the example, explains why Germany becomes a modern battlefield. To his point of view, that is because the weak national character of Germans, and because the modern roads were deprived from them. Then he explains the association between the genre of tragedy and the geography of German from four aspects: life, money, discourse customs and description of events. Moretti's theory provides us that, we can explore the geographical expressions of different literature genres created in the same region, study details in literature works like rhetoric devices and themes, in order to examine the deep reasons on the brilliant achievements of contemporary Shaanxi novels.

At the same time, the core concept of literary geography is "literature landscape". The research on literature landscape can also follow the same path. Different literary genres can express different 
landscapes and imagination spaces, while individual experiences on space must be concentrated in landscapes. Thus, the landscape naturally becomes the carrier of meaning or the object of meaning deconstruction. Take the comparison between Big Wild Goose Pagoda, a suite of poem by modern hazy poet Lian Yang and About Big Wild Goose Pagoda by Han Dong as an example: the former takes the Big Wild Goose Pagoda as the symbolic subject, in which the experience in the river of history is expressed vividly, showing the poet's thoughts and exploration on country and culture. In the poem, numerous images form a vast historical space. There are not too many images in the latter poem, for the purpose of interpreting the Big Wild Goose Pagoda itself as carrier of abundant historical implications, providing some philosophical prediction, and making it impossible to tell all about Big Wild Goose Pagoda erecting in realistic environment, nor the world, society and life. From modern times to contemporary times, the genre of modern vernacular poetry remains the same, but the expression styles of poets have changed. In modern misty poetry, poets tend to express meaning through suitable images. But contemporary poets abandon the depiction of objects and metaphors. They pursue to overthrow meanings, and have the weakest sense of space. Therefore, the same literary landscape has different connotations and meanings in contemporary life. On one hand, poet's feeling has characteristics of the times. On the other hand, feelings of the poet also represent the special methods used to describe emotions in specific eras.

Overall, the basic research objects of Literary Geography are authors and literature works, and the basic research methods are deep reflections of geographic spaces. When interpret authors and literature works, we should make full use of existing methods of resources, investigate corresponding issues from all perspectives, and pay attention to the observation of nature, as well as the expressing and understanding of geographical space. Thus, unique ideas and visions on authors and literary works can be formed. On the other hand, we need to attach importance to the geographic spaces in texts, and their association with psychology, aesthetics and forms. Only in this way, can we find the hidden things ignored by previous studies, and represent the significance of research, which is the core value of contemporary Marxist Literary Criticism.

\section{Acknowledgement}

Fund Project: This project is one of the outcomes of the research, The Literary Geography Research of Shaanxi Novels in the New Century, which is supported by Foundation for Special Research Programs of Education Department of Shaanxi Provincial Government. Project number: 16JK2071.

\section{References}

[1] [3] [4] [5] [9] F. Mulhern. Ed. Contemporary Marxist Literary Criticism: Introduction, Trans. Xiang-yu Liu, Yong-guo Chen, Hai-liang Ma, Peking University Press, Beijing, 2002.

[2] J.X. Liu, Cultural and Geographical Perspective of Literary Criticism, J. Journal of Literature and Art. 2 (2014).

[6] A. Hettner, Geography: History, Nature and Methods, Trans. Lan-sheng Wang, the Commercial Press, Beijing, 1986.

[7] B. Gaston, The Poetics of Space, Trans. By Yi-jing Zhang, Shanghai Translation Publishing House, Shanghai, 2009.

[8] M. Wang, The Preface of Stylistics Series: Stylistics and Creation, Yunnan People's Publishing House, Kunming, 1994. 